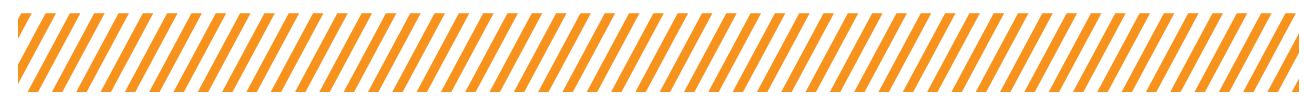

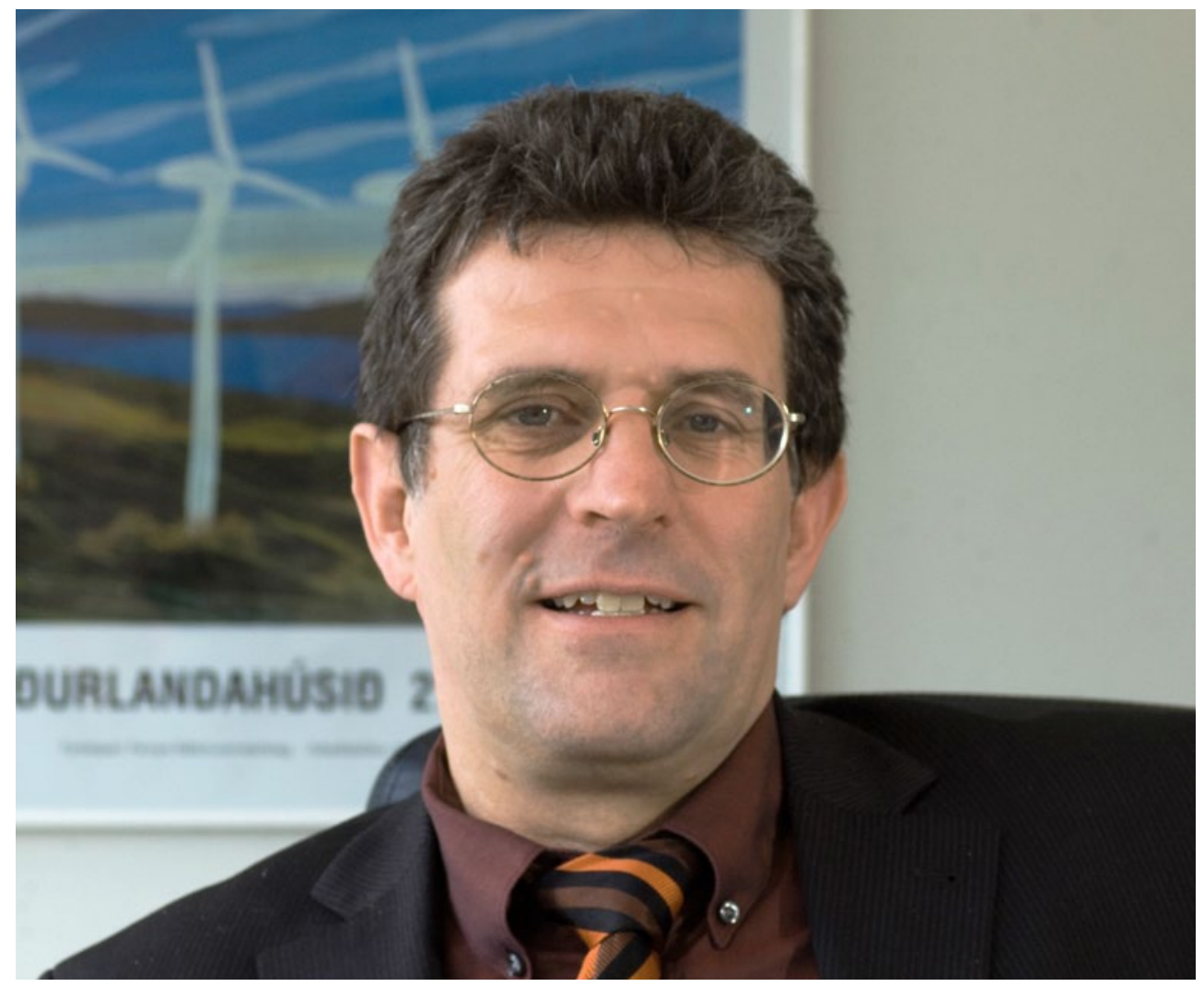

PROF. DR. WERNER TILLMETZ

Vorstandsmitglied des Zentrums für Sonnenenergie- und

Wasserstoff-Forschung BadenWürttemberg (ZSW) sowie Leiter des Geschäftsbereichs Elektrochemische Energietechnologien

\section{FAKTEN FÜR BATTERIE-ZELLFERTIGUNG}

Bisher gibt es in Europa nur begrenzt detaillierte Kenntnisse zur Fertigung von Lithium-Ionen-Zellen. Welche Prozessabschnitte, Fertigungstoleranzen und Inline-Sensorik sind entscheidend - hinsichtlich Kosten und Qualität der Zellen? Noch besteht erheblicher Forschungs- und Entwicklungsbedarf, um die Produktion dieser Schlüsseltechnologie in Deutschland zu etablieren.

Mit dem 2011 am Standort Ulm eröffneten ZSW-Labor für Batterietechnologie (eLaB) wurde ein wichtiger Schritt für den Kompetenzaufbau zu Zell- und Herstelltechnologien in Deutschland unternommen. Mit der Erweiterung des eLaB, dem Aufbau der sogenannten Forschungsproduktionslinie, wird in Deutschland die letzte Lücke im vorwettbewerblichen Umfeld geschlossen. Seriennahe Fertigungsprozesse von großen prismatischen Zellen mit einer Kapazität von mehr als 20 Ah und Außenmaßen nach DIN-Standards, beispielsweise für Elektroautos, werden hier künftig erforscht und weiterentwickelt. Die Anlage wird so ausgelegt, dass mit ihr mindestens 300 Zellen pro Tag mit reproduzierbarer, hoher Qualität gefertigt werden können.

Beim ZSW können in Ulm damit neue Materialien und Komponenten in Hinblick auf die Verarbeitbarkeit und Qualität im industrierelevanten Umfeld evaluiert werden. Es entsteht eine vorwettbewerbliche Entwicklungsplattform, die den seriennahen Gesamtproduktionsprozess abbildet. Durch den modularen Aufbau können Unternehmen und auch Forschungsorganisationen entlang der gesamten Wertschöpfungskette neue leistungsstärkere Verfahren und Anlagenkomponenten in einer prozesssicheren Testumgebung erproben, ohne in eine kommerzielle Zellproduktion eingreifen zu müssen. Besonders mittelständischen Unternehmen bieten sich Möglichkeiten, innovative Konzepte für Komponenten, Prozesse und Qualitätssicherungsmaßnahmen zu erproben.

Um die deutschlandweit einmalige Anlage aufzustellen, wird das eLaB in Ulm um einen vierten Gebäudetrakt erweitert. Das Bundesministerium für Bildung und Forschung fördert die Anlagenausrüstung mit 23,5 Millionen Euro in der ersten Phase. Die Gebäudeerweiterung erfolgt mit der Unterstützung des Landes Baden-Württemberg in Höhe von sechs Millionen Euro. Führende deutsche Industrieunternehmen des Industrieverbunds Kompetenznetzwerk Lithium-Ionen-Batterien e.V. (KLiB) unterstützen die Aktivitäten und sehen in der Technologieplattform einen entscheidenden Faktor für den Aufbau einer starken deutschen Zell- und Batterieindustrie. Die Anlage wird nach heutigem Plan 2014 in Betrieb genommen. 